Correlates of comorbid depression, anxiety and helplessness with Obsessive Compulsive Disorder in Chinese adolescents

\author{
Jing Sun ${ }^{1 *}$, Zhanjiang Li ${ }^{2 *}$, Nicholas Buys ${ }^{3}$, Eric A. Storch ${ }^{4}$ \\ Published in
}

Journal of Affective Disorders 174 (2015) 31-37 


\title{
Correlates of comorbid depression, anxiety and helplessness with Obsessive Compulsive Disorder in Chinese adolescents
}

\author{
Jing Sun ${ }^{1 *}$, Zhanjiang $\mathrm{Li}^{2 *}$, Nicholas Buys ${ }^{3}$, Eric A. Storch ${ }^{4}$
}

*Contribute equally to the paper

${ }^{1}$ Dr Jing Sun, PhD

Griffith Health Institute and School of Medicine, Griffith University, Q4222, Australia

Email: j.sun@griffith.edu.au

${ }^{2}$ Professor Zhan-Jiang Li, MD, PhD

Department of Clinical Psychology, Beijing Key Lab of Mental Disorders; Beijing Anding Hospital, Capital Medical University; Beijing, China. 100088

Center of Schizophrenia; Beijing Institute for Brain Disorders, Beijing, China 100088

Email: Lizhj8@ccmu.edu.cn

${ }^{3}$ Professor Nicholas J. Buys, PhD

Griffith Health Institute, Griffith University, Q4222 Australia

Email: n.buys@griffith.edu.au

${ }^{4}$ Professor Eric A. Storch

All Children's Guild Endowed Chair and Professor, Department of Pediatrics, University of South Florida, US.

Rogers Behavioral Health - TampaBay, Tampa,FL, USA

All Children's Hospital - Johns Hopkins Medicine, St.Petersburg, FL, USA

Email: estorch@health.usf.edu

Running head: Obsessive Compulsive Disorders

Word counts: 6130 words

\section{Correspondence can be address to either:}

Dr Jing Sun, PhD

Griffith Health Institute and School of Medicine, Griffith University, Australia Q4222

Email: j.sun@griffith.edu.au

Professor Zhan-Jiang Li, MD, PhD

Beijing Anding Hospital, and Department of Psychiatry and Clinical Psychology, Capital Medical University, Beijing, China.

Email: Lizhj8@ccmu.edu.cn 


\title{
Correlates of comorbid depression, anxiety and helplessness with Obsessive Compulsive Disorder in Chinese adolescents
}

\begin{abstract}
Objectives: Youth with obsessive compulsive disorder (OCD) are at risk of experiencing comorbid psychiatric conditions, such as depression and anxiety. Studies of Chinese adolescents with OCD are limited. The aim of this study was to investigate the association of depression, anxiety, and helplessness with the occurrence of OCD in Chinese adolescents.
\end{abstract} Methods: This study consisted of two stages. The first stage used a cross-sectional design involving a stratified clustered non-clinical sample of 3174 secondary school students. A clinical interview procedure was then employed to diagnose OCD in students who had a Leyton 'yes' score of 15 or above. The second phase used a case-control study design to examine the relationship of OCD to depression, anxiety and helplessness in a matched sample of 288 adolescents with clinically diagnosed OCD and 246 students without OCD.

Results: Helplessness, depression and anxiety scores were directly associated with the probability of OCD caseness. Canonical correlation analysis indicated that the OCD correlated significantly with depression, anxiety, and helplessness. Cluster analysis further indicated the degree of the OCD is also associated with severity of depression and anxiety, and the level of helplessness.

Conclusion: These findings suggest that depression, anxiety and helplessness are important correlates of OCD in Chinese adolescents. Future studies using longitudinal and prospective designs are required to confirm these relationships as causal. 
Key words: depression, anxiety, helplessness, obsessive-compulsive disorders, Chinese adolescents

\section{Abbreviations:}

OCD: obsessive-compulsive disorder

LOI-CV: Leyton Obsessional Inventory

MOCI: Maudsley Obessive-Compusive Inventory

DSM-IV: Diagnostic and Statistical Manual of Mental Disorders IV

ASQ: Attribution Style Questionnaire 
Pediatric obsessive-compulsive disorder (OCD) is a debilitating neurobehavioral anxiety disorder affecting 1-2\% of youth (Bryńska and Wolańczyk, 2005, Canals et al., 2012, Zohar, 1999). Pediatric OCD persists into adulthood without appropriate treatment (Marcks et al., 2011) and individuals with OCD are at risk of experiencing other comorbid psychiatric conditions. Up to 85\% of children with OCD have at least one comorbid diagnosis (Geller et al., 2003, Storch et al., 2008), and 21\% to 75\% experience two or more comorbid disorders (Ivarsson et al., 2008, Langley et al., 2010). The most common co-occurring psychiatric conditions are anxiety and depression (Ivarsson et al., 2008, Peris et al., 2010, Storch et al., 2008).

Although the association between OCD and comorbid depression and anxiety have been reported in Western populations (Swedo et al., 1989, Storch et al., 2008), this association has not been explored in Chinese adolescents with OCD, and no studies have examined the relationship between helplessness and OCD. Comorbid depression occurs in 35-40 \% of youth with OCD (Swedo et al., 1989), with increased severity of OCD being linked to worse depressive symptoms (Canavera et al., 2010, Langley et al., 2010, Peris et al., 2010). Depression exacerbates functional impairments and quality of life (Lack et al., 2009), and lead to complication of treatment outcomes for youth with OCD (Storch et al., 2008).

Comorbid anxiety is even more prevalent than depression, occurring in $50-77 \%$ of youth with OCD (Ivarsson et al., 2008, Langley et al., 2010). Although it has been found that rates of comorbid anxiety disorder in childhood OCD are low, but increase steadily over the course of adolescence and adulthood (Piacentini et al., 2003). The severity of anxiety becomes greater when severity of OCD symptoms increase (Langley et al., 2010). Similar to the effects of depression, the presence of anxiety during treatment may result in a series of poorer social and behavioural outcomes than for adolescents without comorbid anxiety. 
Understanding the extent of comorbid anxiety in youth with OCD in China may assist with positive treatment outcomes in Chinese adolescents.

Obsessive compulsive disorder has also been associated with learned helplessness in studies of adult OCD patients (Wang et al., 2011). According to Attribution Theory (Abramson et al., 1978), an individual who experiences negative events and who perceives them as uncontrollable may subsequently develop feelings of helplessness. These arise from personal factors (internality), persist for a long period of time or are unchangeable (stability), and affect all other aspects of an individual's life (globality). The nature of this helplessness is a result of the attributions given to experiences of uncontrollable, stressful, or negative events (Wang et al., 2011), that are perceived by the individuals as uncontrollable. This dysfunctional attributional style represents a sense of helplessness that may be related to OCD. However, the evidence whether this helplessness is secondary to OCD and is present when triggered by OC symptoms is inconsistent. Thus, the purpose of the current research was to examine depression, anxiety and helplessness in Chinese adolescents to investigate correlates of OCD at this developmental stage.

\section{Method}

\section{Participants}

There were two stages of sample recruitment. In the first stage, a cross-sectional study was conducted, using a stratified clustered sample, to identify non-clinical Chinese adolescents who exhibited significantly elevated obsessive-compulsive symptoms using the Leyton Obsessional Inventory (LOI-CV) as a screening tool (Berg et al., 1986). In the initial screening, four schools with different academic rankings based on the quality of teaching and learning outcomes were selected from two districts in Beijing, China. These included one highly ranked school, two middle ranked schools, and one low ranked school. Three classes 
per grade per school (72 classes) were randomly selected and invited to participate, resulting in 3,221 potential participants aged 12-18 years. Of these students 3,174 agreed to participate in the initial OCD screening test (98.5\% response rate; Table 1). In the initial screening process, 434 (13\%) students scored $\geq 15$ on the LOI-CV, which is consistent with elevated symptoms (Berg et al., 1986).

\section{[INSERT Table 1]}

In the second stage of the study, the 434 students participated in structured interviews using the Structured Clinical Interview for DSM-IV Axis I Disorders-Patient Edition (SCID-I/P, Version 2.0, American Psychiatric Association, 1994) to diagnose the presence of OCD over the previous month. The SCID-I/P assigned clinical severity ratings following a 7point scale $(0=$ not at all, $7=$ very severe $)$ for each diagnosis. Consensus between the two licensed psychiatrists experienced with childhood OCD was high (Intraclass correlation = 0.93). As a result of this diagnostic procedure, 288 students who met criteria on both the SCID and the Maudsley Obessive-Compusive Inventory (MOCI) were diagnosed with OCD which comprised the OCD case group. Two hundred and forty-six adolescents who matched the students in the clinical group in terms of age and gender but were without psychosis diagnosis were recruited into the 'Control' group. All participants were Chinese, predominantly from a middle socioeconomic background, and youth ranged in age from 1218 years $(M=16.94, S D=1.38)$. The methodology of the recruitment and demographic characteristics of participants has been described elsewhere (Sun et al., 2014a, Sun et al., 2014b).

\section{Measures}


Those who met inclusion and exclusion criteria for either the case or control group were administered a series of clinical interview self-report measures, which assessed OCD, depression, anxiety and helplessness, and were validated and presented in simplified Chinese language format.

OCD Clinical Interview Schedule-IV: Clinical interviews were used and focused on the diagnosis of OCD symptoms using the DSM-IV, SCID-I/P, Version 2.0.(American Psychiatric Association, 1994). These 30-minute interviews were conducted with students who had a Leyton Scale score of 15 or more from the first phase screening test. A student experiencing one of the following symptoms in the previous month was diagnosed to have OCD through the interview: compulsive checking and repeating, compulsive washing and cleaning and similar behaviors, or compulsive thoughts. The instrument also assigned clinical severity ratings following a 7 -point scale $(0=$ not at all, $7=$ very severe $)$ for each diagnosis. Consensus between the two licensed clinical psychiatrists specializing in diagnosing childhood OCD was achieved as demonstrated by a high level of agreement using inter-rate agreement Kappa test (kappa=0.93).

The Maudsley Obessive-Compusive Inventory (MOCI; Hodgson and Rachman, 1977) was used to assist with the description of OCD following the DSM-IV interview procedure. The MOCI was used as a continuous measure of OCD symptoms and to assess the association of OCD symptoms with depression, anxiety, and helplessness. The MOCI is a 30item, self-report, symptom-oriented scale with four dimensions: 'compulsive thoughts', 'cleanliness', 'checking', and 'doubting'. The overall reliability of the scale is acceptable $($ Cronbach’s alpha $=0.76)$.

Depression measure: The Chinese Adolescent Depression Scale used consisted of a 20-item, self-report, symptom-oriented scale suitable for Chinese adolescents (Wang et al., 1997). The Chinese version has demonstrated good reliability and validity for Chinese 
secondary school students (Wang et al., 1997). The factor analysis revealed three dimensions: 'depression’, 'concerns about study', and 'loss of interest in study’. The internal reliability and split-half reliability were high, with a Cronbach’s alpha of 0.95 and Spearman-Brown split-half reliability of 0.92 . The cut-off score of 29.5 was chosen based on the receiver operating characteristic (ROC) analysis, which provided 75\% sensitivity and 60\% specificity of OCD.

Anxiety measure: The Chinese Adolescent Anxiety Scale is a 20-item, self-report, symptom-oriented scale suitable for adolescents. It was developed and standardized by a Chinese researcher for secondary school students (Wu, 1999). The questions were asked based on the frequency of the occurrence of the event on a four point Likert scale: 'never', 'rarely', 'a lot of the time', and 'most of the time'. The factor analysis revealed four dimensions: 'upset and panicky feeling', 'somatic complaints', 'headaches and dizziness', and 'physical illness'. The scale demonstrated a high level of reliability, with a Cronbach's alpha of 0.89 and Spearman-Brown split-half reliability of 0.85 (Wu, 1999). The ROC analysis indicated that the cut-off score of 24.5 provided specificity and sensitivity for anxiety of 78.3\% and 74\%, respectively, for the adolescents with OCD.

Helplessness Scale (HS): The helplessness score was calculated by averaging the globality and stability dimension scores of the Attribution Style Questionnaire (Wang et al., 2011). Higher scores (i.e. the highest 25th percentile) indicate abnormal levels of helplessness. The reliability and validity of helplessness scale (HS) was assessed based on a pilot study which was conducted in 260 students aged 14 to 16 from two secondary schools. Twelve questions were selected based on common negative life events in academic and interpersonal domains in Chinese adolescents. Participants were asked to rate from one to seven the impact of a negative event on each of the two subscales of 'stability', and 'globality' from the HS. Two questions were deleted from the pilot study due to their factor loading 
being less than 0.40 . The pilot study resulted in 10 negative events for a total of 20 items distributed evenly among the two subscales. Cronbach’s alpha coefficients for the Chinese version were 0.88 and 0.90 respectively for the globality and stability subscales, and 0.86 for the total scale, indicating high internal consistency. Test-retest reliability was 0.84 and 0.76 for the two dimensions indicating a high level of test-retest reliability in the HP scale.

Confirmatory factor analysis revealed a good model fit level with $\chi^{2}=2.72$, and excellent fit indices level of GFI $=0.91$, AGFI $=0.89, \mathrm{NNFI}=0.91$, and $\mathrm{CFI}=0.92$.

\section{Procedure}

All participants were diagnosed for OCD using a clinical interview procedure by trained clinicians. Following this, all potential participants were assessed in relation to the OCD symptoms using the MOCI, depression, anxiety and helplessness measures by two psychiatric clinicians. Consensus between the two licensed clinical psychiatrists specializing in diagnosing childhood OCD was achieved by high level of agreement with an intra-class correlation coefficient of 0.93. Demographic data (age, gender, grade, and family environment) and clinical characteristics (stressful life events, course of disease, family history, and physical illness history) were also collected during the interview process. Ethical clearance for this study was obtained through the Chinese Academy of Science, Beijing, China, and written consent from the parent and student were obtained after providing them with a detailed description of the study.

\section{Statistical analysis}

STATA statistical package version 13.0 was used for the statistical analyses for this study (StataCorp, 2014). Descriptive analyses were used to describe the characteristics of the participants, including age, gender, academic grade, medical history, and family environment. If there were significant differences between the OCD and 'control' adolescent groups, these factors were controlled for in the subsequent logistic regression model. The predictive value 
of depression, anxiety, and helplessness on OCD was analyzed using a multiple logistic regression model. Canonical correlation analysis was used to analyze the relationship between OCD and depression, OCD and anxiety, and OCD and helplessness. Cluster analysis was used to identify the patterns in students with OCD using the scores for depression, anxiety, and helplessness. The significance level for all analyses was set at a $p<0.05$. As all missing test items had less than 5\% missing data, multiple imputation method with five imputations was used to impute the missing values for all variables included in the analysis (Carlin et al., 2008).

\section{Results}

Table 2 indicates that 163 (56.6\%) males and 125 (43.3\%) females in the OCD group, and146 (59.3\%) males and 100 (40.7\%) females in the control group. There were equal proportions of students across grades 1 to 6 in the secondary school in the OCD group. Most students with OCD (94.3\%) were of Han Chinese nationality, and 90\% were 'only' children (i.e. one child family). The parents of students with OCD had an average education level of 12 years, and an average age of 44.00 (SD: 3.93) for fathers and 42.32 (SD: 3.25) for mothers. The apartment size for students with OCD, per person per family, ranged from less than 15 square meters to more than 26 square meters, with $78.0 \%$ of students living in an apartment with 15-26 square meters per person per family. There were no significant differences between the OCD and control group across all demographic variables including gender, grade, number of children, ethnicity, mother and father’s occupation, mother and father's age and education, and apartment size (see Table 2).

Further analysis using a Chi-square test was conducted to compare the differences between males and females in the prevalence of high levels of attribution styles, depression and anxiety among students with OCD. The findings indicated no significant difference in the 
proportion of students who had high levels of internality $\left(\chi^{2}=4.48, p=0.11\right)$, globality $\left(\chi^{2}=\right.$ 3.43, $p=0.18)$, stability $\left(\chi^{2}=4.85, p=0.09\right)$, depression $\left(\chi^{2}=1.74, p=0.19\right)$, and anxiety $\left(\chi^{2}=\right.$ $0.09, p=0.76$ ) between the male and female groups.

\section{[INSERT Table 2]}

Table 3 shows the prevalence of depression, anxiety and helplessness among students with OCD according to grade. The findings indicate an increasing prevalence of depression, anxiety and high level of helplessness at higher grade levels.

\section{[INSERT Table 3]}

Table 4 shows the multiple logistic regression results regarding the association between depression, anxiety, and helplessness with OCD. As there were no significant differences between OCD and control group in all demographic variables, these factors were not considered as confounding factors in the logistic regression model. Results indicated that the OCD group outcome variables (i.e., depression, anxiety, helplessness) were independent variables in the analysis. It was found that depression was significantly and positively associated with $\mathrm{OCD},(O R=2.66 ; 95 \% \mathrm{CI}=1.17-5.84, p=0.02)$, as was anxiety $(O R=5.04$, 95\% CI=3.17-8.02, $p<0.001)$, and helplessness $(O R=1.55 ; 95 \% \mathrm{CI}=1.23-1.97, p<0.001)$. These predictors explained $30.2 \%$ of the variance $\left(R^{2}=0.302, \chi^{2}=107.66, p<0.001\right.$, classification rate 73\%). The probability of having OCD symptoms in the OCD group was 2.66 and 5.04 times higher than that of the control group when the depression and anxiety scores, respectively, increased by one unit. The probability of having OCD was 1.55 times 
higher in the OCD group, compared with students in the control group, when the helplessness score increased by one unit.

\section{[INSERT Table 4]}

\section{OCD and depression}

Table 5 displays the canonical correlation results between OCD and depression, anxiety, and helplessness. The canonical correlation produced three pairs of canonical variates. The first canonical correlation was $0.52(p<0.001)$, representing $26.98 \%$ overlapping variance between the first pair of variates. In the first dimension of the four OCD factors, compulsive thoughts and doubting shared variates with factors of depression and concerns of study in the Depression Scale. The second and third canonical correlations were $0.19(p=0.07)$ and $0.06(p=0.53)$, representing $3.6 \%$ and $0.03 \%$ of the overlapping variance, respectively. Only the first pair of canonical correlations was significant at the 0.001 level, while the second and third pair did not approach statistical significance.

\section{OCD and anxiety}

The canonical correlation analysis demonstrated four pairs of canonical variates. The first canonical correlation was $0.61(p<0.001)$, representing $37.17 \%$ of variance between the first pair of variates. In the first pair of variates of the four OCD factors, compulsive thoughts and doubting were covariates with the three anxiety symptoms of upset and panicky feelings, somatic complaints, and physical illness. The second canonical correlation was $0.24(p=$ 0.02), representing $5.6 \%$ of the overlapping variance. Of the four OCD factors, compulsive thoughts, checking, and resistance to change were identified as covariates of the anxiety symptoms of upset and panicky feelings and physical illness. The third and fourth 
correlations were $0.11(p=0.35)$ and $0.06(p=0.35)$, representing $1.2 \%$ and $0.03 \%$ of the overlapping variance, respectively. Only the first and second pairs of canonical correlations were significant at the 0.05 level, while the third and fourth pairs did not approach statistical significance.

\section{OCD and helplessness}

In the canonical correlation between OCD and helplessness, three pairs of canonical variates were revealed. The first canonical correlation was $0.39(p<0.001)$, representing $15.2 \%$ overlapping variance between the first pair of variates. In the first pair of the four OCD factors, compulsive thoughts and doubting were found to covariate with the globality and stability dimensions of the helplessness. The second and third canonical correlations were $0.19(p=0.13)$ and $0.07(p=0.56)$, representing $3.6 \%$ and $0.04 \%$ of the overlapping variance, respectively. Only the first pair of canonical correlations was significant at the 0.001 level (as seen in Table 5), while the second and third pair did not approach statistical significance

\section{[INSERT Table 5]}

Table 6 shows the hierarchical cluster analysis results. These indicate that the three clusters of students with OCD were identified based on the depression, anxiety and helplessness scores. Cluster 1 represents a mild level across the depression, anxiety and helplessness scores, with average scores of 5.99, 23.89, and 3.48, respectively. Cluster 2 represents a moderate level across the depression, anxiety and helplessness scores, with average scores of 21.53, 30.66, and 3.95, respectively. Cluster 3 represents a severe level across the depression, anxiety and helplessness scores, with average scores of 44.58, 39.48, and 4.32, respectively. There were significant differences between the three clusters in the 
depression, anxiety and helplessness scores. The mild, moderate, and severe levels represent $55.8 \%, 33.9 \%$, and $10.3 \%$ respectively, of the students in the OCD group.

\section{[INSERT Table 6]}

\section{Discussion}

The prediction of an statistically significant association between depression and OCD was supported by logistic regression in this study, a finding consistent with the results of Lewis and Waschbusch (2008). An intuitive hypothesis is that as the severity of OCD worsens, so does depression severity (Piacentini et al., 2003, Wu, 1999). The present study supports the suggestion that rates of depression increase when an adolescent's age increases. This supports the argument that depressive symptoms may be secondary to OCD for adolescents Langley et al. (2010), and the argument that older age is associated with higher rates of comorbid depressive disorders among children and adolescents with OCD (Piacentini et al., (2003). The notion that increased age is associated with greater risk for depression has not yet been explored within the context of adolescent OCD, and the present study was the first to demonstrate such evidence.

Logistic regression analysis in the present study indicated a strong association between OCD symptoms and anxiety that OCD adolescents have a 5.04 times likelihood of having anxiety compared to control group adolescents. It was also found that the level of anxiety was substantial for a high percentage of students with OCD in grades 1 (71.2\%) and 2 (64.6\%), but even more so for grades 3 to 6 (80-90\%). The high prevalence of anxiety in OCD adolescents is consistent with Geller et al. (1996). However, the present study expands on these findings, providing evidence that the increasingly high percentages of anxiety from grades 1 to 6 suggests that it may also be secondary to OCD, and that OCD may worsen 
when adolescents get older in situations where OC symptoms are not treated at onset. The level of abnormal helplessness also showed an increasing rate as adolescents aged. This suggests that a high percentage of abnormal levels of helplessness may also be secondary to OCD.

Learned helplessness was significantly related to OCD in Chinese adolescents. Specifically, the occurrence of OCD was significantly related to the globality dimension of helplessness, which aligns with data from adults with OCD (Wang et al., 2011). Although we cannot conclude causality, the significant association between globality and OCD in the present study may be due to adolescents' perception of events as being outside their control and this has extensive impact on their lives.

Continuous investigation using cluster analysis further raises the question of a causal relationship between OCD and depression, anxiety, and helplessness. One avenue not explored in previous studies is whether OCD after a negative event is often expressed as a combination of a high level of depression with helplessness, or a high level of anxiety, or depression alone with helplessness. This study's further research using cluster analysis found support that with the increasing severity level of obsessive-compulsive symptoms, the level of depression, anxiety and helplessness also increased. It is also interesting to note that the total MOCI scores correlated significantly with depression, and anxiety, and the total scores for helplessness, thereby demonstrating that increasing severity in OCD is associated with increasing severity in depression and anxiety, and a high level of helplessness.

The canonical correlation analysis further confirmed that OCD shares a certain degree of variance with depression, anxiety and helplessness, suggesting the symptoms of OCD in adolescents have unique characteristics and may consist of a number of symptoms including OC, depression, anxiety, and feelings of helplessness. It is notable that these subscales, including depression and concerns of the Depression Scale, upset and panic, somatic 
complains and physical illness of the Anxiety Scale, and globality and stability of the HS, are significantly related to the compulsion and doubting of the MOCI scale, and thus explain the relationship between depression and OCD, anxiety and OCD, and helplessness and OCD. Previous studies reported depression and anxiety were prevalent among adolescents with OCD (Fireman et al., 2001, Geller, 2006, Leonard et al., 2001, Peris et al., 2010), but the extent of the overlaps among the symptoms of OCD, depression, anxiety, helplessness were not reported. Therefore, this needs to be assessed when an OCD diagnosis is conducted and may have implications for the treatment of youth with comorbid OCD, depression, anxiety, and feelings of helplessness. To prevent deteriorating OCD symptoms, potential treatment of adolescents with OCD should focus on treatment of depression and anxiety symptoms, and assist them to develop an adaptive style in which they are able to cognitively interpret adverse events as temporary and not necessarily impacting on all aspects their lives.

The study has several limitations. First, the case control design precludes causal statements. Second, the sample was selected from an urban area; thus, generalizability must be treated with caution. Finally, the study sample was non-clinical in nature and thus, may not extend to clinical participants.

\section{Conclusion}

This study found that high attributional scores in globality were associated with a high probability of having OCD. Over $20 \%$ of the adolescents with OCD had depression, while over $80 \%$ had anxiety, suggesting an association between OCD and depression, anxiety and helplessness, in adolescents with OCD. Canonical correlation analysis indicated that OC symptoms overlapped with depression, and anxiety, and helplessness. Cluster analysis examined the common patterns among the depression, anxiety and hopelessness scores, mild, moderate, and severe—based on a combination of the three scores. These findings suggest that depression, and anxiety and helplessness are important indicators for identifying 
OCD. Future studies using longitudinal and prospective study design are required to confirm the association between depression, anxiety and helplessness, with OCD. 
Table 1. Distribution of sample across grade and gender in secondary school students in each grade

\begin{tabular}{|c|c|c|c|c|c|c|c|}
\hline & \multicolumn{2}{|c|}{ Highly ranked school } & \multicolumn{2}{|c|}{ Middle ranked school } & \multicolumn{2}{|c|}{ Low ranked school } & \multirow[t]{2}{*}{ Total } \\
\hline & Boys & Girls & Boys & Girls & Boys & Girls & \\
\hline Year 1 & 63 & 49 & 189 & 163 & 49 & 32 & 545 \\
\hline Year 2 & 47 & 42 & 188 & 193 & 52 & 39 & 561 \\
\hline Year 3 & 55 & 49 & 185 & 187 & 44 & 38 & 558 \\
\hline Year 4 & 57 & 49 & 189 & 174 & 35 & 43 & 547 \\
\hline Year 5 & 54 & 47 & 166 & 176 & 59 & 19 & 521 \\
\hline Year 6 & 43 & 43 & 148 & 137 & 41 & 30 & 442 \\
\hline Total & 319 & 279 & 1065 & 1030 & 280 & 201 & 3174 \\
\hline
\end{tabular}


Table 2. Comparison between control and OCD group in adolescents and their parents demographic

characteristics

\begin{tabular}{|c|c|c|c|c|}
\hline Variables & Control group & OCD group & $\chi^{2}$ or t ratio & $\mathrm{P}$ \\
\hline \multicolumn{5}{|l|}{ Gender } \\
\hline Male n(\%) & $146(59.3)$ & $163(56.6)$ & \multirow[t]{2}{*}{$\chi^{2}=0.41$} & \multirow[t]{2}{*}{0.52} \\
\hline Female $n(\%)$ & $100(40.7)$ & 125 (43.3) & & \\
\hline \multicolumn{5}{|l|}{ Age } \\
\hline Grade 1 n(\%) & 44 (17.9) & $52(18.1)$ & \multirow[t]{6}{*}{$\chi^{2}=0.67$} & \multirow[t]{6}{*}{0.99} \\
\hline Grade 2 n(\%) & $40(16.3)$ & $48(16.7)$ & & \\
\hline Grade 3 n(\%) & $44(17.9)$ & $58(20.1)$ & & \\
\hline Grade 4 n(\%) & $50(20.3)$ & $56(19.4)$ & & \\
\hline Grade 5 n(\%) & $28(11.4)$ & $29(10.1)$ & & \\
\hline Grade 6 n(\%) & 40 (16.3) & $45(15.6)$ & & \\
\hline \multicolumn{5}{|l|}{ Number of children } \\
\hline Only child n(\%) & $226(91.9)$ & $265(92.0)$ & \multirow[t]{2}{*}{$\chi^{2}=0.004$} & \multirow[t]{2}{*}{0.95} \\
\hline 2 or more children $n(\%)$ & $20(8.1)$ & $23(8.0 \%)$ & & \\
\hline \multicolumn{5}{|l|}{ Ethnicity } \\
\hline Han n(\%) & $232(94.3)$ & $267(92.7)$ & \multirow{2}{*}{$\chi^{2}=0.56$} & \multirow[t]{2}{*}{0.46} \\
\hline Others n(\%) & $14(5.7)$ & $21(7.3)$ & & \\
\hline \multicolumn{5}{|l|}{ Mother's occupation n(\%) } \\
\hline Manager of public sector & $6(2.3)$ & $9(3.1)$ & \multirow[t]{6}{*}{$\chi^{2}=7.09$} & \multirow[t]{6}{*}{0.21} \\
\hline Professionals & $134(54.5)$ & $137(47.6)$ & & \\
\hline Entrepreneurs & $11(4.5)$ & $15(5.2)$ & & \\
\hline Office officers & 39 (15.9) & $35(12.2)$ & & \\
\hline Skilled and unskilled workers & $47(19.1)$ & $75(26.0)$ & & \\
\hline Services & $9(3.7)$ & $17(5.9)$ & & \\
\hline Mother's age Mean(SD) & $42.72(3.22)$ & $42.32(3.25)$ & \multirow[t]{2}{*}{$\mathrm{t}=1.41$} & \multirow[t]{2}{*}{0.16} \\
\hline Mother's education Mean(SD) & $12.07(2.74)$ & $11.70(2.85)$ & & \\
\hline \multicolumn{5}{|l|}{ Father's occupation n(\%) } \\
\hline Manager of public sector & $17(6.9)$ & $22(7.6)$ & \multirow[t]{6}{*}{$\chi^{2}=5.28$} & \multirow[t]{6}{*}{0.38} \\
\hline Professionals & $116(47.1)$ & $129(44.8)$ & & \\
\hline Entrepreneurs & $9(3.7)$ & $4(1.4)$ & & \\
\hline Office officers & $32(13.0)$ & $46(16.0)$ & & \\
\hline Skilled and unskilled workers & $61(24.8)$ & $79(27.4)$ & & \\
\hline Services & $11(4.5)$ & $8(2.8)$ & & \\
\hline Father's age Mean(SD) & 43.99 (3.89) & $44.00(3.93)$ & $\mathrm{t}=-0.01$ & 0.99 \\
\hline Father's education Mean(SD) & 12.53 (3.39) & $12.26(3.26)$ & $\mathrm{t}=0.92$ & 0.36 \\
\hline \multicolumn{5}{|l|}{ Apartment size } \\
\hline Less than 15 square metre & $30(12.2)$ & $49(17.0)$ & \multirow[t]{3}{*}{$\chi^{2}=2.58$} & \multirow[t]{3}{*}{0.46} \\
\hline $15-26$ square metres & $192(78.0)$ & $215(74.4)$ & & \\
\hline More than 26 square meters & $24(9.8)$ & $24(8.3)$ & & \\
\hline
\end{tabular}


Table 3. Depression,anxiety and helplessness in adolescents with OCD according to grade

\begin{tabular}{|c|c|c|c|c|c|c|c|c|}
\hline & Subgroup & Year 1 & Year 2 & Year 3 & Year 4 & Year 5 & Year 6 & Total \\
\hline \multirow[t]{4}{*}{ Depression } & No depression & 44 & 40 & 44 & 41 & 19 & 31 & 219 \\
\hline & & $84.6 \%$ & $83.3 \%$ & $75.9 \%$ & $73.2 \%$ & $65.5 \%$ & $68.9 \%$ & $76.0 \%$ \\
\hline & Depression & 8 & 8 & 14 & 15 & 10 & 14 & 69 \\
\hline & & $15.4 \%$ & $16.7 \%$ & $24.1 \%$ & $26.8 \%$ & $34.5 \%$ & $31.1 \%$ & $24.0 \%$ \\
\hline \multirow[t]{4}{*}{ Anxiety } & No anxiety & 15 & 17 & 10 & 11 & 2 & 7 & 62 \\
\hline & & $28.8 \%$ & $35.4 \%$ & $17.2 \%$ & $19.6 \%$ & $6.9 \%$ & $15.6 \%$ & $21.5 \%$ \\
\hline & Anxiety & 37 & 31 & 48 & 45 & 27 & 38 & 226 \\
\hline & & $71.2 \%$ & $64.6 \%$ & $82.8 \%$ & $80.4 \%$ & $93.1 \%$ & $84.4 \%$ & $78.5 \%$ \\
\hline \multirow[t]{4}{*}{ Helplessness } & Normal & 40 & 26 & 44 & 37 & 20 & 21 & 188 \\
\hline & & $76.9 \%$ & $54.2 \%$ & $75.9 \%$ & $66.1 \%$ & $69.0 \%$ & $46.7 \%$ & $65.3 \%$ \\
\hline & Abnormal & 12 & 22 & 14 & 19 & 9 & 24 & 100 \\
\hline & & $23.1 \%$ & $45.8 \%$ & $24.1 \%$ & $33.9 \%$ & $31.0 \%$ & $53.3 \%$ & $34.7 \%$ \\
\hline
\end{tabular}


Table 4. Predictive of OCD by depression, anxiety and helplessness by multiple logical regression analysis

\begin{tabular}{lllll}
\hline & OCD group & Control group M & Odds ratio & $p$ \\
& Mean (SD) & Mean (SD) & (95\% Confidence & \\
& $(\mathrm{n}=288)$ & $(\mathrm{n}=246)$ & Interval) & \\
\hline Depression & $19.92(14.80)$ & $9.33(9.29)$ & $2.66(1.17-5.84)$ & 0.02 \\
Anxiety & $29.75(8.23)$ & $7.93(3.85)$ & $5.04(3.17-8.02)$ & $<0.001$ \\
Helplessness & $3.85(0.94)$ & $3.31(1.01)$ & $1.55(1.23-1.975)$ & $<0.001$ \\
\hline
\end{tabular}

Statistical significance: $p<0.05$ 
Table 5 Canonical correlation analysis on the relationship of OCD to attributional style, depression, and anxiety

\begin{tabular}{|c|c|c|c|c|c|c|c|c|c|}
\hline & & & Canonical & $\mathrm{SE}^{\mathrm{b}}$ & $\mathrm{t}$ & $p$ & $95 \% \mathrm{CI}$ & Wilk F & $\mathrm{R}^{2 \mathrm{C}}$ \\
\hline & & & \multicolumn{7}{|l|}{ Correlation } \\
\hline & & & \multicolumn{7}{|l|}{ Coef $^{\mathrm{a}}$} \\
\hline & $1^{\text {st }}$ & Compulsion & 0.27 & 0.03 & 8.49 & $<0.001$ & $0.21-0.33$ & & $26.98 \%$ \\
\hline & & & & & & & & $8.45^{* * *}$ & \\
\hline \multirow[t]{3}{*}{ OCD } & set & Cleanliness & -0.05 & 0.04 & -1.33 & 0.18 & $0.13-0.03$ & & \\
\hline & & Checking & -0.03 & 0.06 & -0.54 & 0.59 & 0.15- 0.09 & & \\
\hline & & Doubting & 0.16 & 0.06 & 2.57 & 0.01 & $0.04-0.28$ & & \\
\hline \multirow[t]{5}{*}{ Depression } & $2^{\text {nd }}$ & Depression & 0.07 & 0.01 & 4.81 & $<0.00$ & $0.04-0.10$ & & \\
\hline & & & & & & 1 & & & \\
\hline & set & Concern study & 0.11 & 0.04 & 2.76 & 0.01 & $0.03-0.19$ & & \\
\hline & & Lost interests & 0.00 & 0.05 & -0.03 & 0.98 & $0.11-0.10$ & & \\
\hline & $1^{\mathrm{st}}$ & Compusion & 0.22 & 0.02 & 9.03 & $<0.001$ & $0.17-0.27$ & $9.69 * * *$ & $37.17 \%$ \\
\hline \multirow[t]{4}{*}{ OCD } & set & Cleanliness & 0.02 & 0.03 & 0.49 & 0.63 & $0.05-0.08$ & & \\
\hline & & Checking & 0.07 & 0.05 & 1.41 & 0.16 & $0.03-0.16$ & & \\
\hline & & Doubting & 0.18 & 0.05 & 3.65 & $<0.001$ & $0.08-0.27$ & & \\
\hline & $2^{\text {nd }}$ & Upset Panic & 0.16 & 0.03 & 6.15 & $<0.001$ & $0.11-0.21$ & & \\
\hline \multirow[t]{4}{*}{ Anxiety } & Set & Somatic & 0.10 & 0.05 & 2.00 & 0.05 & $0.01-0.19$ & & \\
\hline & & Dizziness & 0.04 & 0.06 & 0.70 & 0.48 & $0.08-0.16$ & & \\
\hline & & Physical & 0.11 & 0.05 & 2.15 & 0.03 & $0.01-0.21$ & & \\
\hline & & Illness & & & & & & & \\
\hline \multirow[t]{5}{*}{ OCD } & $1^{\mathrm{st}}$ & Compulsion & 0.22 & 0.045 & 4.95 & $<0.001$ & $0.12-0.31$ & & $15.20 \%$ \\
\hline & & & & & & & & $4.28 * * * *$ & \\
\hline & set & Cleanliness & -0.03 & 0.06 & -0.45 & 0.66 & $0.14-0.09$ & & \\
\hline & & Checking & -0.11 & 0.09 & -1.22 & 0.22 & $0.28-0.07$ & & \\
\hline & & Doubting & 0.31 & 0.1 & 3.24 & $<0.001$ & $0.12-0.50$ & & \\
\hline \multirow[t]{3}{*}{ Helplessnes } & 2nd & Globality & 0.52 & 0.14 & 3.61 & $<0.001$ & $0.24-0.81$ & & \\
\hline & & & & & & & & & \\
\hline & set & Stability & 0.42 & 0.14 & 2.95 & 0.003 & $0.14-0.71$ & & \\
\hline
\end{tabular}

Notes. ${ }^{\text {a }}$ refers to coefficient, ${ }^{\mathrm{b}}$ refers to standard error, ${ }^{\mathrm{c}}$ is canonical correlation

$* P<0.05, * * P<0.01, * * * P<0.001$ 
Table 6 Cluster analysis on clusters of students with OCD

\begin{tabular}{|c|c|c|c|c|c|c|}
\hline & $\begin{array}{l}\text { Cluster } 1 \\
\text { (Mild) } \\
(\mathrm{n}=104)\end{array}$ & $\begin{array}{c}\text { Cluster } 2 \\
\text { (Moderate) } \\
(\mathrm{n}=50)\end{array}$ & $\begin{array}{l}\text { Cluster } 3 \\
\text { (Severe) } \\
(n=134)\end{array}$ & $\mathrm{F}$ & $p$ & Post Hoc \\
\hline Depression & $5.99(4.13)$ & $21.53(5.62)$ & $44.58(11.06)$ & 606.78 & $<0.001$ & $\begin{array}{l}\text { Clusters } 2>1 * * * \\
\text { Cluster } 3>1 * * * \\
\text { Custer } 3>2 * * *\end{array}$ \\
\hline Anxiety & $23.89(5.10)$ & $30.66(6.51)$ & 39.48 (7.43) & 108.65 & $<0.001$ & $\begin{array}{l}\text { Custer } 2>1 * * \\
\text { Cluster } 3>1 * * * \\
\text { Cluster } 3>2 * * *\end{array}$ \\
\hline Helplessness & $3.48(0.87)$ & $3.95(0.84)$ & $4.32(1.07)$ & 16.49 & $<0.001$ & $\begin{array}{l}\text { Clusters } 2>1 * * * \\
\text { Cluster } 3>1 * * * \\
\text { Clusters } 3>2 *\end{array}$ \\
\hline
\end{tabular}

Notes. $* P<0.05,{ }^{* *} P<0.01, * * * P<0.001$ 


\section{References}

Abramson, L. Y., Seligman, M. E. \& Teasdale, J. D. 1978. Learned helplessness in humans: critique and reformulation. J Abnorm Psychol, 87, 49-74.

American Psychiatric Association 1994. Diagnostic and statistical manual of mental disorders (DSM-IV). Washington, DC: American Psychiatric Association.

Berg, C. J., Rapoport, J. L. \& Flament, M. 1986. The Leyton Obsessional Inventory-Child Version. J Am Acad Child Adolesc Psychiatry, 25, 84-91.

Bryńska, A. \& Wolańczyk, T. 2005. Epidemiology and phenomenology of obsessivecompulsive disorder in non-referred young adolescents: a Polish perspective. Eur Child Adolesc Psychiatry, 14, 319-327.

Canals, J., Hernández-Martínez, C., Cosi, S. \& Voltas, N. 2012. The epidemiology of obsessive--compulsive disorder in Spanish school children. J Anxiety Disord, 26, 746752.

Canavera, K. E., Ollendick, T. H., Ehrenreich May, J. T. \& Pincus, D. B. 2010. Clinical correlates of comorbid obsessive-compulsive disorder and depression in youth. Child Psychiatry Hum Dev, 41, 583-594.

Carlin, J. B., Galati, J. C. \& Royston, P. 2008. A new framework for managing and analyzing multiply imputed data in Stata. Stata Journal, 8, 49-67.

Fireman, B., Koran, L. M., Leventhal, J. L. \& Jacobson, A. 2001. The prevalence of clinically recognized obsessive-compulsive disorder in a large health maintenance organization. Am J Psychiatry, 158, 1904-1910.

Geller, D. A. 2006. Obsessive-compulsive and spectrum disorders in children and adolescents. Psychiatr Clin North Am, 29, 353-370.

Geller, D. A., Biederman, J., Griffin, S., Jones, J. \& Lefkowitz, T. R. 1996. Comorbidity of juvenile obsessive-compulsive disorder with disruptive behavior disorders. J Am Acad Child Adolesc Psychiatry, 35, 1637-1646.

Geller, D. A., Biederman, J., Stewart, S. E., Mullin, B., Farrell, C., Wagner, K. D., Emslie, G. \& Carpenter, D. 2003. Impact of comorbidity on treatment response to paroxetine in pediatric obsessive-compulsive disorder: is the use of exclusion criteria empirically supported in randomized clinical trials? J Child Adolesc Psychopharmacol, 13 Suppl 1, S19-S29.

Ivarsson, T., Melin, K. \& Wallin, L. 2008. Categorical and dimensional aspects of comorbidity in obsessive-compulsive disorder (OCD). Eur Child Adolesc Psychiatry, 17, 20-31.

Lack, C. W., Storch, E. A., Keeley, M. J., Geffken, G. R., Ricketts, E. D., Murphy, T. K. \& Goodman, W. K. 2009. Quality of life in children and adolescents with obsessivecompulsive disorder: base rates, parent-child agreement, and clinical correlates. Soc Psychiatry Psychiatr Epidemiol, 44, 935-942.

Langley, A. K., Lewin, A. B., Bergman, R. L., Lee, J. C. \& Piacentini, J. 2010. Correlates of comorbid anxiety and externalizing disorders in childhood obsessive compulsive disorder. Eur Child Adolesc Psychiatry, 19, 637-645.

Leonard, H. L., Freeman, J., Garcia, A., Garvey, M., Snider, L. \& Swedo, S. E. 2001. Obsessive-compulsive disorder and related conditions. Pediatr Ann, 30, 154-160.

Lewis, S. P. \& Waschbusch, D. A. 2008. Alternative approaches for conceptualizing children's attributional styles and their associations with depressive symptoms. Depress Anxiety, 25, E37-E46. 
Marcks, B. A., Weisberg, R. B., Dyck, I. \& Keller, M. B. 2011. Longitudinal course of obsessive-compulsive disorder in patients with anxiety disorders: a 15-year prospective follow-up study. Compr Psychiatry, 52, 670-677.

Peris, T. S., Bergman, R. L., Asarnow, J. R., Langley, A., McCracken, J. T. \& Piacentini, J. 2010. Clinical and cognitive correlates of depressive symptoms among youth with obsessive compulsive disorder. J Clin Child Adolesc Psychol, 39, 616-626.

Piacentini, J., Bergman, R. L., Keller, M. \& McCracken, J. 2003. Functional impairment in children and adolescents with obsessive-compulsive disorder. J Child Adolesc Psychopharmacol, 13 Suppl 1, S61-S69.

StataCorp. 2014. STATA Statistical Analysis [Online]. New York: StataCorp.

Storch, E. A., Merlo, L. J., Larson, M. J., Geffken, G. R., Lehmkuhl, H. D., Jacob, M. L., Murphy, T. K. \& Goodman, W. K. 2008. Impact of comorbidity on CognitiveBehavioral Therapy response in pediatric Obsessive-Compulsive Disorder. J Am Acad Child Adolesc Psychiatry, 47, 583-592.

Sun, J., Boschen, M. J., Farrell, L. J., Buys, N. \& Li, Z. J. 2014a. Obsessive-compulsive symptoms in a normative Chinese sample of youth: prevalence, symptom dimensions, and factor structure of the Leyton Obsessional Inventory-Child Version. $J$ Affect Disord, 164, 19-27.

Sun, J., Li, Z., Buys, N. J., Storch, E. A. \& Wang, J. 2014b. Obsessive-compulsive symptoms and personal disposition, family coherence and school environment in Chinese adolescents: A resilience approach. J Affect Disord, 168, 459-465.

Swedo, S. E., Rapoport, J. L., Leonard, H., Lenane, M. \& Cheslow, D. 1989. Obsessivecompulsive disorder in children and adolescents. Clinical phenomenology of 70 consecutive cases. Arch Gen Psychiatry, 46, 335-341.

Wang, C., Zhang, J., Li, J., Zhang, N. \& Zhang, Y. 2011. Attribution retraining group therapy for outpatients with major depression disorder, generalized anxiety disorder, and obsessive-compulsive disorder: a pilot study. J Biomed Res, 25, 348-355.

Wang, J. S., Qiu, B. W. \& He, E. S. 1997. Validation and normalisation of secondary school students depression scale. Social and Psychological Science, 3, 1-3.

Wu, W. Y. 1999. Manual psychological health assessment: anxiety self-report scale. Chinese Journal of Mental Health, supplement, 235-238.

Zohar, A. H. 1999. The epidemiology of obsessive-compulsive disorder in children and adolescents. Child Adolesc Psychiatr Clin N Am, 8, 445-460. 


\section{Supplement figure}

Caption:

Figure 1: ROC curve analysis for depression measure.

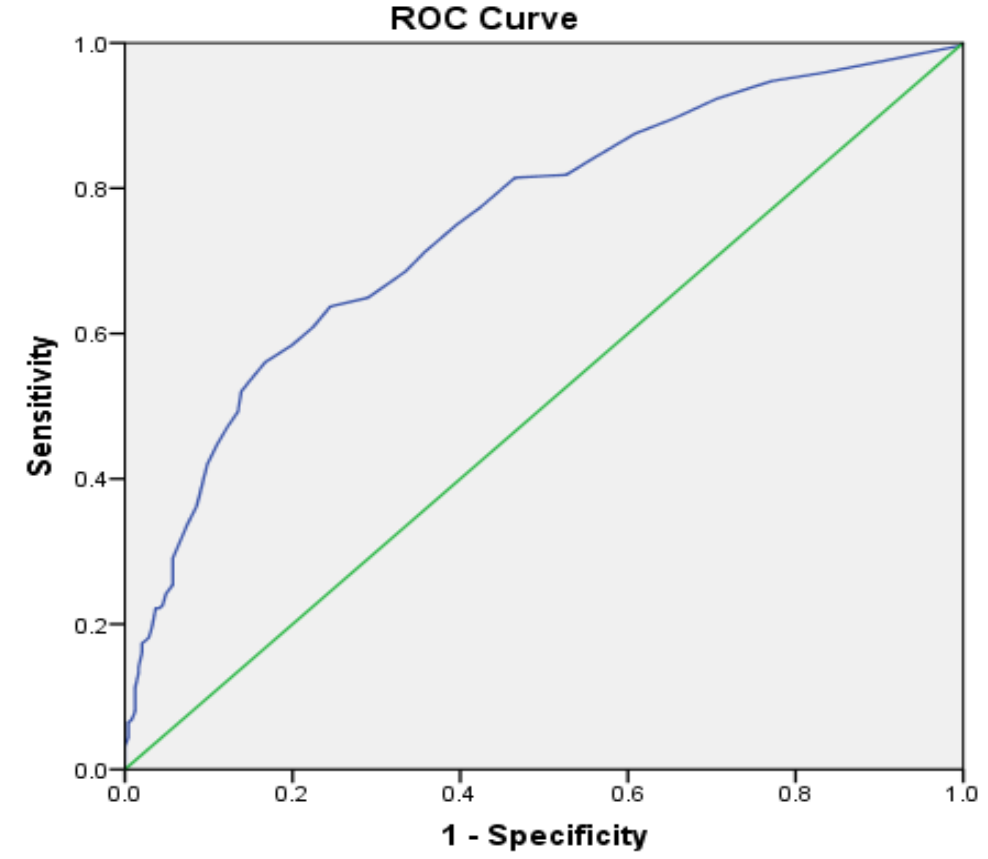

Diagonal segments are produced by ties 